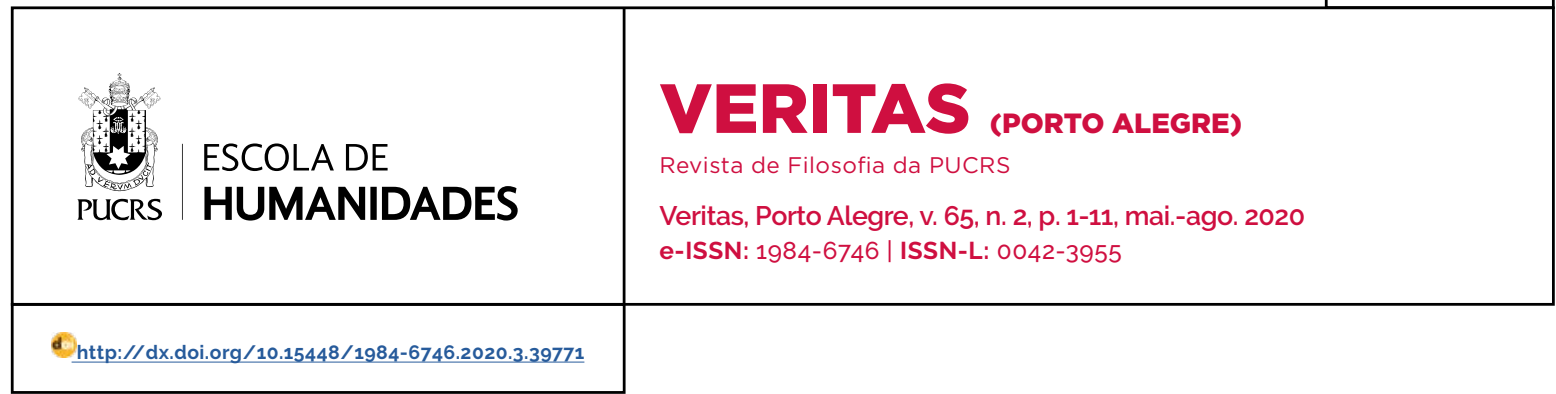

\title{
¿Una teoría de las cinco sustancias en Marsilio Ficino? ${ }^{1,2}$
}

\author{
A Theory of Five Substances in Marsilio Ficino's Thought?
}

Teresa Rodriguez ${ }^{3}$

materogo@gmail.com
Resumen: Este texto explora la llamada teoria de las cinco sustancias que ha caracterizado la interpretación de la ontología ficiniana desde que Kristeller publicó su libro El pensamiento filosófico de Marsilio Ficino. Su objetivo principal es cuestionar su pertinencia a partir del análisis del primer capitulo del Libro I de la Teología Platónica con el fin de evidenciar que no es claro que los cinco grados de lo real puedan ser identificados con el término "sustancia" en el trabajo de Ficino. A partir de la confrontación de algunos pasajes que caracterizan su noción de "cualidad" y de su Comentario al Parménides se propone que es más adecuado calificar como "sustancia" solamente los tres primeros grados de la jerarquía y que, por tanto, la interpretación tradicional de la ontología ficiniana no es exacta. Palabras clave: Renacimiento, sustancia, Plotino, Proclo, Ficino

Abstract: In this paper I explore the so-called theory of five substances that has characterized the traditional interpretation of Ficino's ontology since Kristeller published his book The philosophy of Marsilio Ficino. My point of departure is the first chapter of Book I of his Platonic Theology. I seek to demonstrate that it is not clear that the five degrees of reality can be identified as "substances" in Ficino's text. From the comparison of this chapter with certain passages in his Parmenides' Commentary, I propose that it is more appropriate to describe only the first three degrees as "substances". Therefore, the traditional interpretation of Ficino's ontology is not accurate.

Palabras clave: Renaissance, substance, Plotinus, Proclus, Ficino

El objetivo de este trabajo es cuestionar la pertinencia de calificar la ontología ficiniana fundamental como una teoría de las cinco sustancias. Tradicionalmente se ha aceptado que la ontología de Ficino se basa en tal teoría proponiendo un orden jerárquico de lo real en cinco grados que se identifican como "substancias". Para mostrar que esto no es preciso en primer lugar expongo los antecedentes de la noción platónica de substancia que operan en la ontología ficiniana. En segundo lugar, examino los grados de esta ontología como aparecen en el libro I, capítulo 1 de la Teología Platónica (en adelante TP) y localizo los lugares donde se encuentra el término substancia en dicho paso; argumento que no puede aplicarse a los cinco grados de lo real en consonancia con los antecedentes mencionados. Por último, traigo a colación ciertas afirmación encontradas en el Comentario al Parménides de Ficino para subrayar que 
calificar el núcleo de la ontología ficiniana como una teoria de las cinco substancias es erróneo.

\section{Antecedentes. Substancias y cualidades}

Como es sabido, el término sustancia tiene una larga tradición. Entre otros muchos significados, la tradición filosófica inmediatamente anterior a Ficino, es decir, la medieval, anota (1) la estructura necesaria del ente, es decir, lo que es primariamente constitutivo de algo, asociado con el concepto de esencia; (2) el sentido de subsistencia que implica la independencia ontológica; (3) el soporte de los accidentes que perdura en el ser por debajo de los cambios que sobrevienen (Magnavacca, 664-665). Esta última acepción remite a Categorias V4. Alli, Aristóteles afirma que la substancia primaria es aquella que "ni se dice de un sujeto, ni está en un sujeto" (2a11), es decir, aquello que no necesita de otra cosa para darse. Aristóteles identifica estas substancias con los individuos, como el hombre o el caballo individual. Asi "todas las demás cosas, o bien se dicen de las substancias primarias como de sus sujetos, o bien están en ellas como en sus sujetos" (2 $\left.2^{\mathrm{a}} 33-35\right)$. Por ello, si no existieran estas substancias seria imposible que "existiera nada de lo demás" (2b5-6). Las especies a las que pertenecen estas substancias son llamadas substancias segundas.

Frente a esta acepción, el uso del término 'sustancia' en el libro I de la TP de Ficino, parece ligarse de manera más cercana a la tradición platónica. A menudo, cuando Ficino habla de "los platónicos", se refiere a Plotino5, quien sostiene que las entidades sensibles individuales no son sustancias ${ }^{6}$, por contraposición a Aristóteles, y que están constituidas por cualidades. Si regresamos a Aristóteles, en Cat. VIII la cualidad es una categoria diferente a la substancia: es "aquello según lo cual algunos se llaman tales o cuales" (8b25-26) y necesita, para darse, a las substancias primeras. La cualidad "se dice de varias maneras" (8b27) y puede referir a un estado (conocimientos o virtudes) o disposición (el calor, la enfermedad, la salud), las capacidades (tener capacidad natural para hacer algo con facilidad), las cualidades afectivas y afecciones (dulzura, amargura, acritud).

Así, es posible distinguir entre la sustancia primera (por ejemplo, la miel) y su cualidad (dulce)7. Las cualidades (o al menos algunas) admiten la contrariedad, el más y el menos. Además, admiten lo semejante y lo desemejante de manera exclusiva ("en efecto, una cosa no es semejante a otra más que en la medida en que es tal o cual. De modo que será exclusivo de la cualidad el que se diga en relación con ella lo semejante y lo desemejante" (11 $\left.{ }^{\mathrm{a}} 17-19\right)$. Así, substancias y cualidades pertenecen a dos categorias distintas: las últimas necesitan de las primeras para darse.

Plotino (II.6), por su parte, considera la sustancia en relación a dos niveles. El inteligible y el sensible. Respecto a los seres inteligibles, "la sustancia tiene un significado más pleno de autoridad y de pureza; y se da también en las diferencias del ser" (II.6.1.53-55). En el sensible, sin embargo, se habla de "sustancias" solo en un sentido derivado e impropio. Afirma que "en lo que atañe a las cosas sensibles, ninguna [...] es una sustancia, sino sólo afecciones de ella" (II.6.1.50-52) ya que "que lo que ha llegado a ser no es enteramente una sustancia" (1.51-52). Las entidades sensibles son un "conglomerado de cualidades y materia" (VI.3.8 20-21). Este conjunto de cualidades y materia es a veces calificado de sustancia, pero no es "sustancia verdadera. sino remedo de la verdadera (la inteligible), de la que sin los accesorios anejos a aquella posee su Ser; las demás se originan de ella, ya que ella era Ser en el verdadero sentido. Acá, en cambio,

\footnotetext{
4 Otra forma de abordar el problema, como lo hace Karamanolis (2009), es a partir de Met. Z. Sin embargo, si nos constreñimos a Categorías es posible mostrar con mayor claridad el contraste con la posición plotiniana. Es importante señalar, asimismo, que además de las substancias sensibles en sentido fuerte (que no tienen que darse en otra cosa para existir y que no se predican de otra cosa), existen substancias incorpóreas más básicas que éstas (en el sentido de que son su causa), como el primer motor. Cfr. Met. $\Lambda$.

5 En el capítulo I, 2, 8 y en 3, 25, por ejemplo.

6 "Todo ser corpóreo está sujeto a la generación y no es una sustancia; esto es, se dice que nace y que perece y que no es nunca verdaderamente; si se conserva, se conservará precisamente por su participación en el ser y en tanto dure esta participación". Enneada IV.8. 7 Otro tipo de cualidades, son la figura y la forma (la derechura, la curvatura, lo triangular, etc).
} 
el sustrato es infecundo e incapaz de ser ente, porque tampoco se originan en él las demás cosas. Es sombra y, sobre esta sombra, pintura y apariencias" (VI.3.8 33-37).

Plotino rechaza la división aristotélica, presente en Categorias, entre sustancias primeras y segundas en al menos dos pasajes. Para él, en todo caso, la sustancia en sentido primario será la inteligible, "las demás, en sentido secundario y en menor grado"8 (6.1.3 4-6). Además, en 6.3.9-10, Plotino afirma que la distinción aristotélica entre sustancias primeras (este fuego) y sustancias segundas (fuego) difieren en que una es particular y la otra universal, pero esto no constituye una diferencia substancial ya que también en la cualidad se da esta distinción entre "una blancura. y "blancura" y "una gramática" y "gramática". Siguiendo el ejemplo de la gramática, se afirma que "la gramática no es posterior a la gramática particular, antes bien, porque existe la gramática, existe también la que hay en ti, pues que aun la que hay en ti es particular porque está en ti, pero en sí misma es idéntica a la universal" (6.3.9. 24-27). El cuestionamiento de la relación entre particulares y universales lleva a Plotino a trasladar el acento de la substancia a la cualidad, puesto que un hombre particular es tal hombre: Sócrates, por ejemplo. Hemos visto que ser tal indica la cualidad. Plotino afirma: "Además, ¿qué puede ser Sócrates sino "tal hombre"? Y lo "tal" qué contribuye a que sea más substancia9?" (30-31).

Cabe añadir que Plotino distingue, con otros platónicos ${ }^{10}$, las formas inmanentes (en la materia) y las Formas trascendentes, separadas. Sólo las entidades inteligibles trascendentes (tales como dichas Formas, el Intelecto y el Alma) tienen naturalezas o esencias: "Esto significa que sólo estas entidades son $\mathrm{F}$ o $\mathrm{Y}$, y pueden predicarse verdaderamente como tales, mientras que las sustancias sensibles nunca son totalmente $F$ o $Y$, sino que siempre están en proceso de llegar a ser F o Y" (Karamanolis, 81). La forma particular, que se encuentra en Sócrates, es una cualidad de un cuerpo. La Forma en sí es anterior a la forma en la materia.

Esto implica que ontológicamente las formas inmanentes tienen un bajo estatus en la gradación plotiniana, inferior al de las sustancias ${ }^{11}$.

Así, tenemos que una teoría neoplatónica de la sustancia difiere de la presentado en Categorias $\checkmark$ por Aristóteles en varios puntos:

a. Las entidades del mundo sensibles no son substancias en sentido pleno sino cúmulos de cualidades.

b. No se admite la distinción entre sustancias primeras y sustancias segundas tal como la encontramos en Categorias V.

c. La sustancia, en sentido pleno, es la inteligible. Las entidades sensibles son el resultado de la conjunción de materia y cualidades y sólo en sentido impropio se podrian denominar "substancias".

\section{Los cinco grados de lo real y la teoría de las cinco sustancias}

Estas nociones de substancia y cualidad se verán reflejadas en la ontología que se despliega en TP y que surge a partir de la adopción de

\footnotetext{
8 A este respecto hay dos interpretaciones. Chiaraddona supone que la distinción entre sustancias primeras y segundas se refiere a la distinción entre sustancias inteligibles y "sustancias" sensibles, como se sostiene aquí. Por su parte, Lavaud piensa que la distinción se da en el mundo inteligible solamente entre la substancia en general y las substancias particulares pero inteligibles: "To better understand the gap between particular substances and the primary substance, it is necessary to distinguish between two ways of determining ousia:

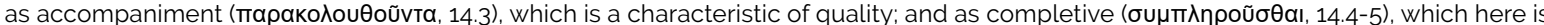
only reserved for the great kinds. With an eye to illustrating the first method. Plotinus takes the example of 'composite substances that are made up of many elements' (14.6). The expression is ambiguous: one may think that it refers to sensible realities made up of matter and form; yet here Plotinus contents himself with intelligible realities, as he announced in the beginning of the treatise [...]" (373)

9 De nuevo, Lavaud matiza esta posición, por oposición a Karamanolis: "Of course, as we have highlighted on numerous occasions, in the treatises On the Kinds of Being Plotinus tends to deny sensible reality any consistent ousia. Thus, sensible ousia and intelligible ousia only seem to have a common name (ó $\mu \omega v u ́ \mu \omega \varsigma$, Treatise $42(6.1), 1.21$ ). However, it is in its sensible capacity that Socrates' reality is deprived of all substantiality-Socrates' body, if it is only a 'conglomeration of qualities and matter' (Treatise 44 (6.3), 8.20 ) is by no means an ousia. On the other hand, if this same reality is grasped by the intelligence, and no longer by only the senses, his ousia can reappear: Socrates has both an internal unity and structure, his being can be defined by thought". (378).

10 Por ejemplo, en el Didascalicus. (Cfr. Lloyd, 59).

11 Las entidades sensibles entonces consisten en cualidades en una forma muy especifica, en el sentido de que se parecen a las sustancias reales. Esto es porque las sustancias reales, que son entidades trascedentes, hacen aflorar estos parecidos de si mismas a través de su actividad en la materia. Plotino encuentra el término "cualidad" adecuado para portar el sentido de algo que se parece a una sustancia. De esta forma, "cualidad" se aplica especialmente a la forma inmanente (Karamanolis, 96).
} 
un postulado de gradación de lo real que. partiendo de los textos de Plotino, se desarrollará posteriormente en los trabajos de sus seguidores hasta llegar a Proclo. La ontología ficiniana se constituye por cinco grados, a saber: (1) Dios, (2) la Mente Angélica, (3) el Alma Racional, (4) la Cualidad y (5) el Cuerpo ${ }^{12}$. Tradicionalmente esta gradación es conocida como la "teoría de las cinco sustancias" de Ficino. Según Kristeller, esta teoría constituye el logro más acabado en cuanto a su metafísica se refiere. En ella, Ficino "experimenta" con el esquema plotiniano con el fin de subrayar el carácter ontológicamente excepcional del alma. El esquema plotiniano que Kristeller privilegia para sustentar su posición despliega seis grados, a saber: Uno, mente, alma, sensación, naturaleza y cuerpo ${ }^{13}$. De esta forma, según Kristeller, "[Ficino] elimina las dos partes inferiores del alma -esto es, sensación y naturaleza-e introduce la Cualidad como un nuevo elemento. Así, tiene un esquema simétrico de cinco sustancias"14. Según Allen, Kristeller sostiene a lo largo de su obra esta posición afirmando que esta teoría fue el resultado (impresionante) de la especulación ficiniana y que construye la centralidad del alma en una jerarquía ontológica comprensiva (cfr. Allen, 1982, p. 20).

Más recientemente, en 2011, Enrico Vitale continúa utilizando el concepto de la teoria de las cinco sustancias en su introducción a la TP: "En los años de madurez, él [Ficino] hace de la doctrina de las cinco sustancias uno de los puntos cardinales de su sistema filosófico [...]" (Vitale, 2011, LX). Según Vitale, "en el capítulo introductorio a su obra principal, Ficino se propone como objetivo primario la demostración de la doctrina de las cinco sustancias, fundamental para proceder a la demostración completa de la inmortalidad del alma" (Vitale, 2011, LX). El objetivo central de esta sección es examinar los principales presupuestos de dicho capítulo con el fin de evaluar la pertinencia de caracterizarla ontología ficiniana como una teoría de las cinco sustancias. Antes, sin embargo, conviene apuntar brevemente el esquema general de la obra.

\section{II.1 La organización de la TP}

Si abrimos TP, las primeras páginas parecen corroborar la posición de Kristeller. En el capítulo primero del Libro I, Marsilio Ficino sostiene que, si el hombre no tuviera un alma inmortal y pereciera como otras criaturas, sería el más infeliz de los seres creados:

\begin{abstract}
Ya que el alma humana siempre está inquieta y el cuerpo es débil y en todas las cosas indigente, la vida en la tierra es más dura que la de las bestias. Si la naturaleza hubiera puesto el término a su vida como a la de los otros animales, ningún animal sería más infeliz que el hombre. El hombre, sin embargo, por el culto a Dios se acerca a Dios, el autor de la felicidad, más que otra cosa mortal. En ningún modo puede ser posible que sea el más infeliz de todos. Pero sólo después de la muerte del cuerpo puede llegar a ser más feliz. Es necesario que nuestras almas, al dejar esta prisión, aguarden alguna otra luz (TP I.1.7) ${ }^{15}$.
\end{abstract}

Así pues, para Ficino, es necesario demostrar por una serie de argumentos que el alma es inmortal. Para ello, se propone establecer en primer término un recorrido ontológico en el que se establezca la jerarquía mencionada y muestre que además de la masa del Cuerpo, el puesto (5)

12 En adelante, los grados de la ontología ficiniana aparecerán en mayúsculas con el fin de distinguirlos claramente.

13 Para Plotino, en III, 4, 1 sensación, naturaleza y cuerpo son los tres últimos niveles de lo real. Por contraste en V, 2, 1 sensación y naturaleza son el "ídolo" o la imagen del alma. La cualidad aparece en IV.2.1 como el grado intermedio entre el alma y el cuerpo "Hay, por tanto, y en primer lugar, un ser indivisible que actúa como guia de las

realidades inteligibles; pero, a la vez, se da otra esencia completamente dividida en

las realidades sensibles. Y aun pudiéramos hablar de una tercera, que se halla antes

de lo sensible, muy cercana a él e incluso en él; esta naturaleza no se encuentra

primitivamente dividida, como los cuerpos, sino que se divide cuando viene a los

cuerpos. Al estar los cuerpos divididos, la forma que se da en ellos también se

divide; no obstante, se aparece toda entera en cada una de las partes que resultan,

como si la forma se multiplicase y cada una de sus partes se separase de las otras,". Cfr. Allen, 1982, p. 20 n. 4-5.

14 Kristeller, The Philosophy of Marsilio Ficino. pp. 400-401. Citado por Allen, 1982. p. 20. El subrayado es mío.

15 Cum genus humanum propter inquietudinem animi imbecillitatemque corporis et rerum omnium indigentiam duriorem quam bestiae vitam agat in terris, si terminum vivendi natura illi eumdem penitus atque caeteris animantibus tribuisset, nullum animal esset infelicius homine. Quoniam vero fieri nequit ut homo, qui Dei cultu propius cunctis mortalibus accedit ad Deum beatitudinis auctorem, omnino sit omnium infelicissimus, solum autem post mortem corporis beatior effici potest, necessarium esse videtur animis nostris ab hoc carcere discedentibus lucem aliquam superesse. 
en su jerarquía ontológica, existe una Cualidad o poder (virtus), el grado (4) en dicha jerarquía, y que, más allá de la Cualidad que es divisible y mutable, existe una forma más alta que aunque es mutable en un sentido, no admite la división en el cuerpo y que ésta es el Alma Racional, el grado (3). Además, sobre esta forma encontramos el grado (2) la Mente Angélica, múltiple pero inmutable, y a Dios, la unidad absoluta y grado (1) de la jerarquía. Así, se establece la existencia de cinco grados de lo real. El alma ocupa el lugar central y es el vínculo que mantiene la naturaleza unida, rige a las cualidades y a los cuerpos y se une al ángel y a lo divino. De esta forma, el itinerario general que nos propone Ficino en TP (que recordemos busca manifestar la inmortalidad del alma) queda determinado por su intento de demostrar:

(1) La indisolubilidad del alma racional en virtud de su carácter vinculante de la naturaleza.

(2) Su excelencia puesto que preside la máquina del mundo.

(3) Su beatitud por su cercanía a lo divino.

Esto se da a través de las siguientes estrategias metodológicas:
a. Demostración por razones generales (ontología).
b. Demostración por argumentos pro- pios sobre la inmortalidad del alma.

c. Signos de su independencia con el cuerpo

d. Solución de cuestiones (principalmente contra las posiciones de Averroes y los epicúreos).

Ficino comienza por establecer su marco ontológico general en los primeros cuatro libros de la obra. En ellos explora la forma en que se organiza lo real proponiendo los cinco grados mencionados. Explora con detenimiento la naturaleza de Dios y la del Alma antes de adentrarse en los argumentos propios que demostrarian su inmortalidad en los libros $\mathrm{V}$ a XII; los libros XIII y XIV exploran una serie de signos que oscilan desde el éxtasis de los poetas hasta los milagros. Los libros XV, XVI y XVII proponen cinco cuestiones sobre el alma. Finalmente, el libro XVIII se centra en algunas puntualizaciones teológicas (como la creación de las almas y la relación entre el platonismo y el cristianismo).

\section{II.2 El uso del término sustancia en TP}

Ahora bien, todo el recorrido descrito anteriormente se sostiene, según la interpretación tradicional, en la teoría de las cinco sustancias. Si esto es así, implica que cada uno de los grados o principios de lo real es una sustancia. Sin embargo, si nos detenemos en los pasajes específicos del primer libro de la TP, Ficino no parece explicitar la equivalencia entre gradus y substantia ${ }^{16}$.

Para comenzar con el análisis, es conveniente notar que la primera vez que aparece el término substantia en la TP es en I.3.7. Antes, con el fin de desplegar los grados de su ontología, Ficino se ha dedicado a la búsqueda de la naturaleza cuya característica consiste en su independencia respecto a la acción. Su búsqueda comienza con el grado (5) de lo real con el fin de establecer que el Cuerpo no actúa por naturaleza propia:

\begin{abstract}
De acuerdo con Platón, el cuerpo se compone de materia y cantidad. A la materia pertenece solamente la extensión y la afección. Y esta extensión y afección son pasiones. La cantidad no es otra cosa que la extensión misma de la materia; o, si es otra cosa, es algo sujeta siempre a división [...] Se sigue que el cuerpo mismo no actúa sino que está sujeto solamente a la pasión (TP I.2.1) ${ }^{17}$.
\end{abstract}

El Cuerpo (5) se compone de materia (de donde es

\footnotetext{
16 Cabe aqui aclarar que Ficino, en su traducción de las Eneadas, vierte el término hipóstasis del título de V.I como sustancia. Sin embargo, en la TP. Ficino utiliza el término gradus para referirse a los distintos niveles de la realidad. En este sentido es interesante notar que Eric Perl, en su reciente traducción de Eneadas V.I. ha optado por traducir el título, impuesto por Porfirio, como "On the Three Primary Levels of Reality", en sustitución de "On the Three Principal Hypostases". La justificación, según Backes, se relaciona con el hecho de que Plotino no utiliza nunca el término hipóstasis.

17 Quoniam corpus apud Platonem ex materia quadam constat et quantitate, atque ad materiam extendi et affici pertinet solum, et ipsa extensio affectioque passiones quaedam sunt, quantitas autem aut nihil est aliud quam extensio ipsa materiae, aut si quid aliud est, est tamen res quaedam talis, ut et divisioni subiecta sit semper, l...]; consequens est ut corpus ipsum, quatenus corpus, agat quidem nihil, sed soli passioni subiiciatur
} 
extenso y sujeto a afecciones) y cantidad (la división de la extensión de la materia). Esta conformación impide que actúe puesto que toda acción requiere de una naturaleza incorpórea que sea potente, pronta al movimiento y que penetre al paciente sobre el que actúa de manera que se una a él.

Estas características corresponden al grado inmediato superior: la Cualidad (4) que es incorpórea e inextensa por sí misma. Los cuerpos actúan a través de una fuerza y una cualidad implantada en ellos. Esta cualidad es un tipo de forma, una forma en la materia: "Llamamos cualidad, de acuerdo con el modo platónico ${ }^{18}$ [de filosofar], a toda forma dividida en el cuerpo" (T.P. I.3.1 ${ }^{19}$. Las cualidades, entonces, son un tipo de formas. Sin embargo, son formas impuras puesto que se encuentra en el seno de la materia. La Cualidad, como forma, tiene como sustrato a la materia y no puede sostenerse por sí misma. Está sujeta entonces a generación y corrupción. Si se genera, afirma Ficino, debe generarse a partir de otra cosa (puesto que nada se genera a si mismo) y esa otra cosa puede ser, o bien, la materia, o bien una forma superior. Si fuera la materia, tendría ésta la virtud de generar

¿[...] por si misma o por otro? Ya que si la tiene por otro, por otro tiene la forma. Y si por sí misma, igualmente, ¿la tienen por otra virtud propia y así procederiamos al infinito o más bien posee aquella virtud no por otro sino por esencia? Si es así, entonces la esencia de la materia misma seria una virtud o una sustancia productora de formas y la fuente de las formas más bien que su substrato. Entonces seria más bien forma que materia y la forma más exce- lente de todas, la forma que no sufre ninguna división ni fluctúa como ahora con la variedad de formas, sino que por su esencia sempiterna las formas sempiternas tendría (TP I.3.7) ${ }^{20}$.

Esto parece implicar que la sustancia es aquello que trae las formas inmanentes al ser, que las crea o produce y que puede igualarse con la esencia. Por ello, la materia no puede ser la causa de las cualidades, puesto que carece de esta virtud creativa. Si no es la materia, debe ser una forma superior. Si la Cualidad no es la forma primera ${ }^{21}$, debe postularse una cuya naturaleza sea simple, eficaz y pronta para la acción. Además, sobre las cualidades debe existir otra instancia que las ordene: "Por tanto, antes y sobre todas las formas de este tipo debe existir una sustancia incorpórea que penetre los cuerpos, cuyos instrumentos sean las cualidades de los cuerpos. Ya que, ¿cómo las cualidades singulares que por naturaleza son inestables y desordenadas, sirven al orden estable en la sucesión de la generación, sino porque son regidas por el orden estable de una causa más alta?" (TP I.3.10)22.

Ficino entonces continúa su argumentación apelando al principio del "primo in aliquo genere". Este principio implica que todo género puede ser conducido a algo uno que sea indivisible dentro de su propio género. Así como el movimiento y el tiempo pueden ser conducidos a un momento y el número a la unidad, asi también el género de las sustancias, afirma Ficino, puede ser retraido a la sustancia indivisible. De acuerdo con esto, el recorrido hacia el primero en su género implica

18 Recuérdese que este modo platónico de filosofar refiere a Plotino.

19 Qualitatem vero more platonico omnem formam divisam in corpore appellamus.

20 Atque de hac ipsa virtute similiter inquiremus, numquid eam habeat a seipsa an ab alio? Quod si habet ab alio, ab alio quoque habet formam; sin a se, numquid hanc similiter habet per aliam virtutem sibi itidem propriam, atque ita in infinitum progrediemur. an potius virtutem illam non per aliam possidet virtutem, sed per essentiam? Si ita est, essentia materiae idem erit ac virtus sive substantia effectiva formarum, et fons erit formarum potius quam subiectum; immo erit forma potius quam materia, et forma omnium praestantissima, forma omnis divisionis impatiens; neque fluctuabit, ut nunc, labentium varietate formarum, sed per essentiam sempiternam formis erit praedita sempiternis.

${ }_{21}$ De nuevo, en referencia a Plotino, Enn.

22 Quamobrem praeter omnes huiusmodi formas inesse oportet omnibus et praeesse substantiam quamdam incorporalem per corpora penetrantem, cuius instrumenta sint corporeae qualitates. Quo enim pacto qualitates singulae, quae suapte natura instabiles inordinataeque sunt, aut stabilem ordinem in generationis successione servarent, nisi per ordinem altioris causae stabilem regerentur.

Además, el recorrido ontológico se comprueba por el recorrido epistemológico: Mens humana quotidie a particularibus formis ad universales absolutasque se confert. Item, super naturales formas certis adstrictas materiis per mathematicas, quibus incerta materia sufficit, ad metaphysicas, quae neque certa, neque incerta materia indigent, ascendere solet. Praeterea, a dimensionibus, quae tam situ quam partibus egent, ad punctum sine partibus, sed quodammodo circa situm: rursus a punctis ad numeros, qui partibus quidem indigent, situ vero nequaquam; demum a numeris ad unitatem, cui neque situ neque partibus ullis opus est, sese attollit. Atque ultra unitatem individuam, sed accidentalem ad substantialem se unitatem, id est formam, transfert individuamque essentiam, accidentium fundamentum simul atque originem, tamquam ad fixum quemdam, et in seipso manentem accidentium per se mutabilium alterique semper haerentium cardinem. Si tantam ad ascensum rationalem mens humana potentiam habet, quae et pars quaedam est universi, et mens corporeis vinculis impedita, multo certe maiorem ad idem in seipso possidet universum, praesertim cum infimae mentis ordo ab universi ordine trahat originem. Ubi vero ad agendum potentia maior viget, ibidem naturaliter et magis et citius proditur in actum. (TP I.3.11). 
ir desde las formas accidentales y divisibles, pasando por la forma que es sustancial ${ }^{23}$ y divisible, hasta la forma sustancial e indivisible (TP I.3.12)24.

Llega asi a la postulación de la sustancia incorpórea, capaz de fortalecer y dirigir a las cualidades corporales y organizarlas. Esta capacidad, afirma Ficino, de robustecimiento y dirección es un tipo de vida: "El orden procede de la razón. La razón consiste en la vida, la vida en una virtud indivisible. Ya que la muerte llega por división y disolución" (TP I.3.12)25.

Las formas corporales no tienen la potencia suficiente para generar algo viviente. Por ello, es necesario postular una causa superior (que no se ligue a la materia, ya que si ésta estuviera también ligada a la materia, entonces sería necesaria la postulación de otra causa superior, etc.). Para evitar la regresión al infinito, Ficino postula la existencia de una forma que no esté mezclada con los cuerpos. Además, incluso quien postulara que las formas están siempre ligadas a la materia y que la separación es sólo conceptual, tendría que aceptar, según Ficino que la mente es separada ya que separa otras cosas. Se llega así, desde el cuerpo y las formas corporales a la forma que subsiste por sí misma, la forma verdadera. Esta es la llamada tercera esencia que debe identificarse como el alma racional.

Con este argumento, Ficino ha buscado probar que es necesaria la existencia de una instancia que garantice la estabilidad de lo que se genera y se corrompe, puesto que las cualidades no son capaces de sostener dicha estabilidad. Para lograr tal garantía, se debe pertenecer a un orden superior, es decir incorpóreo. Tal instancia es identificada como una forma que por su carácter de permanencia y por su potencia creadora de vida es también substancia. Tal substancia es el alma. Los platónicos, dice Ficino, la consideran verdadera e inmortal por las siguientes causas:

(1) No está constituida por partes en las que pudiera disolverse o debilitarse su virtus.

(2) No está ligada a un sustrato que al separarse produzca su desaparición.

(3) No está mezclada con ninguna otra forma que pudiera contaminarla.

(4) No está sujeta a un lugar, tiempo o movimiento ya que es una sustancia indivisible y simple.

La última parte de la argumentación de Ficino, corresponde a la consideración de la tercera esencia respecto al movimiento:

¿Cuál decimos que es la naturaleza de la tercera esencia? ¿Es absolutamente inmóvil o más bien móvil? Ciertamente no del todo inmóvil porque es la fuente de las cualidades que fluyen en la materia, que carecen de toda quietud. Toda causa actúa de acuerdo con su propia naturaleza, de manera que en sus obras se preserva algo de su fuerza y su imagen. Si esta esencia, que es la causa de las cualidades, fuera absolutamente inmóvil, si actuara por su naturaleza del todo inmóvil, la cualidad que desciende de ella retendria en si una naturaleza inmóvil (TP I.4.1) ${ }^{26}$

Si la Cualidad es móvil respecto a sus tres constituyentes (esencia, virtud y acción) y si existe

23 Las sustancias corpóreas que corresponden al principio o grado de la cualidad tendrian que ser referidas no ya a este sentido pleno del término sustancia (equiparable con la esencia que crea o produce formas) sino en un sentido que podriamos denominar débil y que surge del maridaje de respuestas a la vieja controversia entre la tradición aristotélica ly su crítica a las formasl y las tradiciones platónicas. En este sentido, las formas corporales no serían sustancias en sentido platónico (lo que subsiste por sí), sino en sentido aristótelico, qua sustancias primeras. La confusión de estos dos sentidos llevó a los comentaristas neoplatónicos a refinar la relación entre las formas y el concepto de sustancia, a partir justamente, de la concepción gradual de lo real. Cfr. d'Hoine (2011).

24 Accedit ad haec quod si quaelibet rerum genera ad unum quiddam in suo genere quodammodo indivisibile reducuntur, cuius simplicitate consistunt, ut puta, motus tempusque ad momentum, forma naturalis ad gradum minimum naturalem, geometricae dimensiones ad signum, numeri ad unitatem, cur non etiam substantiae genus ad indivisibilem substantiam redigatur? Ut quemadmodum figurae omnes, quae inaequalitatis participes sunt, ad circularem omnium aequalissimam referuntur, circularis ad indivisibile centrum, totius aequalitatis initium, ita formae accidentales divisibilesque ad substantialem divisibilemque formam: forma huiusmodi ad substantialem et indivisibilem reducatur. Atque ut ultra qualitatem, quae non decremento solum, sed etiam remissioni subiecta est, substantialis corporalisque forma est, quae a remissione est libera, quamvis decrescat, ita super hanc esse debet substantialis forma, quae neque remittatur, neque decrescat, ut ascensus, qui in melius proficit, perficiatur in optimo. Talis erit substantia incorporea, quae in primis hoc habet, ut natura sua minui nequeat. Quam oportet alicubi secundum proprio formam in natura subsistere.

25 Ordo a ratione procedit. Ratio consistit in vita. Vita in virtute quadam indivisibili. Siquidem mors divisione et resolutione contingit.

26 Tertiae huius essentiae naturam qualem esse dicemus? Immobilemne prorsus an potius mobilem? Certe non omnino immobilem, quia ipsa fons est qualitatum fluentium in materiam, quae omni quiete carent. Omnis autem causa secundum naturam propriam agit, ideoque oportet in opere vim aliquam et imaginem causae reservari. Si essentia illa, quae est causa qualitatum, esset prorsus immobilis, quia per naturam suam omnino immobilem ageret, qualitas inde descendens immobilem in se naturam aliquam retineret. 
algo en el orden de lo real que sea absolutamente inmóvil, será necesario un intermediario que sea parcialmente móvily parcialmente inmóvil: el Alma. Ésta es una sustancia que causa la cualidad y que por tanto debe exceder a la cualidad respecto a su disposición móvil, es decir, respecto a su esencia. Así, será respecto a su esencia, inmóvil. Respecto a su acción, móvil y respecto a su virtud parcialmente móvil y parcialmente inmóvil:

Hasta aqui descubrimos la forma superior a la complexión del cuerpo, que llamábamos alma racional, cuya esencia siempre permanece igual. Lo que se muestra por la estabilidad de la voluntad y la memoria. Su operación es móvil ya que no puede pensar todas las cosas simultáneamente, sino de manera gradual; tampoco, en un momento nutre, incrementa y genera el cuerpo sino a través del tiempo. La virtud natural permanece, porque su vigor natural florece perpetuamente, ni se intensifica, ni se reduce. La virtud adquirida cambia, porque de la potencia al acto y del acto al hábito transita y viceversa (TP I.5.1 $)^{27}$.

Este cambio de acento hacia el análisis del movimiento le permite a Ficino continuar con su argumentación hacia los grados superiores de la jerarquía (de los cuales no nos ocupamos en este texto): en virtud de su movimiento (aunque parcial), el alma no puede ser el principio de la naturaleza. Se busca entonces una forma o esencia superior a esta que Ficino denomina el Ángel o la Mente Angélica. Este grado, sin embargo, no es totalmente unitario puesto que, aunque inmóvil, existe en ella multiplicidad (de Formas, de ángeles). Debe existir algo que se uno e inmóvil absolutamente y esto es Dios.

En lo anterior hemos presentado la forma en que Ficino despliega su ontología y los argumentos que utiliza para mostrar la necesaria existencia de los cinco grados de lo real. Se han subrayado especialmente los concernientes al nivel de la Cualidad y el Alma para mostrar sus características. En especial, se ha hecho énfasis en el término substancia y en el de forma. Como fue manifiesto, las cualidades son un tipo de formas pero no todas las formas pueden ser consideradas como sustancias para la tradición platónica ${ }^{28}$.Es cierto que el alma es un tipo de forma también, pero por sus caracteristicas es también una sustancia.

Las cualidades son un tipo de formas pero no constituyen una sustancia porque ésta es precisamente la instancia ontológica que genera las formas y posibilita su subsistencia en un substrato material. De esta forma, el texto parece indicar que no todos los niveles o grados de lo real son substancias en el sentido propio. La Cualidad y el Cuerpo no son grados que contengan potencias creadoras. Las cualidades como formas tienen un estatus ontológico inferior. en tanto que formas inmanentes, y no pueden ser calificadas como substancias en sentido estricto, siguiendo la tradición platónica explicitada al inicio de este trabajo con el ejemplo de Plotino.

\section{Conclusión. El Comentario al Parménides y las tres sustancias incorpóreas.}

Postular que la ontología ficiniana responde a una teoría de las cinco sustancias parece arriesgado. Michael Allen (1982) ha cuestionado la originalidad de la teoría, aunque sin cuestionar explícitamente la sustancialidad de los cinco grados de lo real. Como mencionamos, la intervención en el número de grados o principios de lo real y su ordenamiento era para Kristeller una posición original en la que Ficino establecia mediante este postulado ontológico la centralidad del alma. Sin embargo, esta posición es problematizada por Allen, quien ofrece al menos las siguientes razones para revisar la

\footnotetext{
27 Hactenus formam quamdam supra corporis complexionem invenimus, quam rationalem animam appellabimus, cuius essentia semper eadem permanet. Quod significat stabilitas voluntatis atque memoriae. Operatio autem ex eo mutatur quod non simul cogitat omnia, sed gradatim, neque momento alit, auget et generat corpus, sed tempore. Naturalis virtus manet, quia naturalis eius vigor viget perennis, neque intenditur, neque remittitur. Virtus acquisita mutatur, quia ex potentia in actum, ex actu transit in habitum atque converso.

${ }_{28}$ Como afirma Corrigan: "To say simple that substance is form [...] is, in my view, profoundly misleading because it is not yet clear what is included or excluded from the notion of form itself" (303).
} 
posición clásica de Kristeller²9:

a) El esquema plotiniano parece oscilar a lo largo de las Eneadas, de manera que no siempre presenta seis grados ${ }^{30}$.

b) En el Comentario al Simposio, Ficino trabaja con otros esquemas que corresponden a cuatro y seis grados.

Allen propone otra solución a la pregunta sobre la génesis de la teoria de las cinco sustancias. Sin embargo, mantiene la existencia de esta teoria. Se aleja de la hipótesis sobre la originalidad de Ficino para sostener que la fuente del esquema quintuple es en última instancia la lectura neoplatónica del Parménides y su historia tal como se encuentra relatada por Proclo. Tal lectura culminó con la postulación e identificación de las cinco primeras hipótesis del Parménides con el Uno, la Mente, el Alma, las Formas Corporales y la Materia. Allen propone, siguiendo a Saffrey y a Westerink, que en V.1.8. Plotino parece identificar la primera hipótesis del Parménides (137C4) con la primera hipostasis, el Uno. La segunda, (144E5) con la mente (nous) y la tercera (155E5) hipótesis con el alma. En IV.2.2.52-55, según Allen, Plotino tal vez podria identificar la cuarta hipóstasis, las formas en la material ${ }^{31}$, con la cuarta hipótesis (157C6); y por última la materia con el "sujeto de la quinta [hipostasis]"(1982, p. 29). Sin embargo, estas identificaciones se sustentan en evidencias bastantes vagas, sobre todo, las referentes a la cuarta y quinta hipótesis ${ }^{32}$.

Es necesario notar que la distinción que realiza Allen respecto a las posiciones de Plotino y la posterior lectura neoplatónica (de Plutarco de Atenas y de Proclo) no cuestiona el estatus sustancial del cuarto grado de su ontología, sino sólo la fuente que Ficino utilizaría para establecerla y su posible originalidad.

Si regresamos a la posición de Allen, en la cual se derivan los grados de la ontología ficiniana de las hipótesis del Parménides, conviene complementar el análisis con su comentario a este diálogo.

Desde la presentación inicial del argumento del diálogo, Ficino ha establecido que el objetivo

29 Recientemente, Allen ha defendido nuevamente su posición frente a Kristeller: "In sum, Kristeller is mistaken in seeing Ficino's pentadic metaphysical scheme as original, for the reverse is true. Ficino was deeply indebted to Proclus: (a) for his articulation of the fivefold scheme; (b) for arguing that it was Plato's own; and (c) most notably for anchoring it in the Parmenides, the dialogue which thus served as the unassailable bulwark for the Platonic argument that Soul is the universal mean, the third of five universal hypostases. Furthermore, Ficino's Parmenides argumentum provides us with irrefutable evidence of his having engaged Proclus' complex analysis at an early stage in his career as a commentator" Allen (2014) 373. Nótese que en esta ocasión Allen ya no utiliza una referencia a una teoría de las cinco sustancias sino a un esquema quíntuple. Es posible que el uso de la caracterización de la ontología ficiniana como "una teoría de las cinco substancias" suponga una confusión entre las teorías aristotélica y plotiniana de la substancia por parte de Kristeller. Allen, por su parte, al virar el acento hacia Proclo, o bien piensa que él sostiene también una teoria de las cinco substancias o bien supone que tal denominación es válida si se hace equivalente el término substancia con el de hipóstasis. Como apunta Backes (cfr. n. 14 supra), Plotino nunca utiliza el término hipóstasis para referirse a los grados de lo real; además, es disputable el número de estas hipóstasis en sus tratados como se puede ver en la siguiente nota.

30 Al respecto existen varias interpretaciones sobre el número de las hipóstasis. Cfr., por ejemplo, Anton (1977).

31 Sobre la sustancialidad del cuarto grado en la filosofia de Proclo, parece no existir un acuerdo entre los comentaristas. Por un lado, Russi afirma que para Proclo la naturaleza constituye una hipóstasis separada de la del alma y una sustancia incorpórea, que suele identificarse con el destino. Consiste en "the potency in charge of governing those beings which pass away completely, and which coincides with nature itself, is a substance sufficiently unified to provide such beings with an internal order and an indefectible connection. Thanks to its internal unity, fate is also capable of regulating the physical realm in compliance with the motion of the eternal stars" (157) (Cfr. Proclo, Prov. 12 1-12). Una presentación menos clara es propuesta por Martijn, para quien Proclo presenta dos posiciones encontradas respecto a la naturaleza: "In summary, the preceding paragraphs yield the following picture. On the one hand, nature is set apart from soul, because of its immersion into bodies, its divisibility, and its lack of self-sufficiency. On the other hand, that which is called nature primarily, especially in the introduction to the In Tim., is an incorporeal productive cause, and hence, Proclean metaphysics would suggest, a transcendent monad (Nature). (39). Para ella, además la Naturaleza no se identifica con el destino.

32 Cfr. el estudio introductorio de a su traducción francesa de la Teología Platónica de Proclo de Saffrey y Westernik para una historia de la lectura de las hipótesis del Parménides en la tradición platónica. Allen resume ésta de la siguiente manera: "lamblichus, who accepted Porphyry's division into nine hypotheses but likewise failed to identify all their subjects correctly; he did, however, insist that the opening hypotheses each signified the differing subdivisions within a hypostasis as well as the hypostasis itself. A major breakthrough came with a mysterious thinker, "the philosopher of Rhodes" who made the critical discoveries that the hypotheses were divided into two classes, the positive and the negative, and that the two classes corresponded. Having identified the first five hypotheses with the One, Mind, Soul, Bodily Forms, and Matter, he felt compelled, however, to postulate five parallel negative hypotheses, and ended up with ten instead of nine hypotheses and also a series of incorrect correspondences.The last major and -in the Neoplatonic view- definitive breakthrougth came with Plutarch of Athens, the man who held the chair at the Athenian Academy when Proclus first arrived there, though he was then too old to lecture (he died in 43 or 432). Plutarch succeeded in reconciling the division into nine hypotheses with the discoveries of the philosopher of Rhodes, first by accepting the first five hypotheses as positive and identifying them respectively with God, Mind, Soul, Forms united with Matter, and Matter, All of them requiring unity, that is, the existence of the One; and then by accepting the last four hypotheses as negative. Plutarch also accepted the notion of a correspondence between the positive and negative hypotheses. He achieved a perfect symmetry here by arguing that we do not require a negative hypothesis to correspond to the first positive hypothesis". (1982. p. 30). 
de éste es la búsqueda del principio de todas las cosas, el Uno: "Hay que notar que cuando se menciona el Uno en este diálogo, puede indicar [...] cualquier sustancia singular que esté totalmente separada de la materia como Dios, la mente y el alma. Pero cuando los términos otro u otras cosas son usados deben ser entendidos como la materia y las cosas [formas] que sean en la materia" (In Parmenidem, p. 108)33.

Así, la cita anterior parece indicar que para hablar de la sustancia es necesario que ésta sea incorpórea (Dios, mente o alma) y que los otros dos grados de lo real (que tienen relación con el cuerpo y la materia) no se consideran sustancias en sentido pleno, sino principios:

La primera hipótesis trata del Dios primero La segunda del intelecto primero y de todo el orden intelectual. La tercera trata del alma e igualmente de su orden. La cuarta trata de las formas [species] materiales. La quinta trata la materia informe. Ya que estos son los cinco principios de todas las cosas. Tres de éstos son principios separados, pero los dos últimos cumplen su obra en la materia. [...] Parménides se refiere a cada una de las sustancias separadas como uno, por su simplicidad. Pero a la materia y la forma corpórea los llama otro y las otras cosas por su flujo y su diversidad, muy distantes de lo divino (In Parmenidem, p. 134)

De esta manera parece que la adopción de una teoria de las cinco sustancias para caracterizar la ontología ficiniana no es del todo adecuada y que disminuye la fuerza de la argumentación respecto a la preeminencia delalma. Los principios o grados del ser no son equivalentes con la sustancialidad de los mismos. La sustancia es, en sentido estricto, incorpórea y comienza ontológicamente hablando en el grado correspondiente al alma. Así, podriamos hablar de una teoria donde tres de los cinco principios de lo real son sustancias. Esta lectura no disminuye el peso de la prueba sobre la centralidad del alma ni sobre la importancia de ésta en el pensamiento ficiniano, sino que implica que además de su centralidad ontológica tiene a la vez preeminencia sustancial sobre los dos principios inferiores: la cualidad y el cuerpo.

\section{Bibliografía}

ALLEN, Michael, 1982, "Ficino five substances and the Neoplatonist's Parmenides", Journal

of the Medieval and Reinassances Studies, vol. 12, n. 1, pp. $18-45$

ALLEN, Michael, 2014, "Marsilio Ficino", en Gersh, Stephen (ed), Interpreting Proclus. From Antiquity to the Renaissance. Cambridge University Press, Cambridge.

ANTON, John, 1977, "Some Logical Aspects of the Concept of 'Hypostasis' in Plotinus". The Review of Metaphysics, XXXI, 258-71.

ARISTÓTELES, 1982, Tratados de Lógica I, Gredos, Madrid.

BACKES, Christopher, 2016, "Plotinus, Ennead V.I.: On the Three Primary Levels of Reality. Translated by Erick Perl." The Review of Metaphysics; Washington, 69, N. ${ }^{\circ} 4$. 830-832

D'HOINE, Pieter, 2011, "Aristotle's Criticism of Non-Substance Forms and its Interpretation by Neoplatonic Commentator". Phronesis, Volume 56, Issue 3, 262-307.

FICINO, Marsilio, 2001, Platonic Theology, Vol. I. The I Tatti Renaissance Library. London.

FICINO, Marsilio, 1641, "In Parmenidem", en Marsilii Ficini philosophi platonici medici atque theologi omnium praestantissimi, Operum. Tomus secundus. Paris: Guillaume Pelé, 1641.

KARAMANOLIS, George, 2009, "Plotinus on Quality and Inmanent Form", Physics and Philosophy of Nature in Greek Neoplatonism, Brill.

KRISTELLER, Paul Oskar, 1953, Il pensiero filosófico de Marsilio Ficino", G.C. Sansoni Editore, Florencia.

LAVAUD, Laurent, 2014. The Primary Substance in Plotinus' Metaphysics:

A Little-Known Concept. Phronesis 59 369-384.

LLOYD, A.C., 1995, "Neoplatonic Logic and Aristotelian Logic I", Phrónesis, I, 1, 58-72

MAGNAVACCA, Silvia, 2005, Léxico Técnico de Filosofía Medieval. Niño y Dávila. Buenos Aires.

MARTIJN, Marije, 2010, Proclus on Nature, Brill, Leiden. PLOTINO, 1982-1998, Eneadas, Gredos, Madrid.

33 Illud in super aduertendum est, quid in hoc dialogo cum dicitur unum l...] quaque substantia a materia penitus absoluta significari potest, ut Deus, anima, anima. Cum vero dicitur aliud et alia, tam materia, quam illa quae in materia siunt, intelligere licet.

34 Prima suppositio de primo tractat Deo. Secunda, de intellectu primo, et ordine prorsus intelectuali, Tertia, de anima, suoque similliter ordine. Quarta, de materiali specie. Quinta de informi materia. Haec enim quinque rerum principia sunt. Tertia, quidem illa principio separata, duo vero sequentia intrinsecus complent opus. Parmenides l...lunum communiter appellat, propter simplicitatem, substantiam quamlibet separatam. Aliud autem et alia nominat propter fluxum diuersitatemque a diuinis longe distantem, materiam formamque corpoream. 
SAFFREY H. D. y Westernik, L.G., 1968, "Introduction" a Proclus, Theologie Platonicienne. Les Belles Letres, Paris.

RUSSI, Chiara, 2009, "Causality and sensible objects", Physics and Philosophy of Nature in Greek Neoplatonism, Brill.

VITALE, Enrico, 2011, "Saggio Introduttivo", Teologia Platonica, Bompiani, Milano.

\section{Teresa Rodriguez}

Maestra y Doctora en Filosofia por la Universidad Nacional Autónoma de México (UNAM). Investigadora Asociada C del Instituto de Investigaciones Filosóficas de la UNAM. Pertenece al Sistema Nacional de Investigadores del CONACYT. Dirigió el proyecto "Historiografía filosófica y olvidos. El caso del Renacimiento" (2015 a 2016) y actualmente dirige el proyecto "La recepción de la filosofía griega en el Renacimiento y la Modernidad: Aristóteles a través de Diógenes Laercio" (2017 a 2018). Ambos con financimiento de la Dirección General de Asuntos del Personal Académico de la UNAM. Ha publicado los artículos "El modelo biográfico de Diógenes Laercio y la Vita Platonis de Ficino", Praxis filosófica 43 (2016); “¿Una posible polémica entre platónicos sobre Aristóteles? El fragmento 13 del Comentario a una canción de amor de Pico della Mirandola" Tópicos, Revista de Filosofía 50 (2016); "El platonismo florentino ante el problema de la creación de las almas individuales: una aproximación metodológica" en Revista Latinoamericana de Filosofía, Vol. XLI, NN 1, Otoño 2015; "¿Basta con desechar la categoría "neoplatonismo" para rehabilitar a los neoplatónicos? en Signos Filosóficos, No. 33. Enero-julio 2015 y "Orfeo y el neoplatonismo en la Florencia renacentista" en Diánoia, Vol LVIII, no. 71, noviembre 2013. 